\title{
Microencapsulation of natural food colourants
}

\author{
Gülay Özkan*, Seda Ersus Bilek
}

Food Engineering Department, Engineering Faculty, Ege University, Bornova, Izmir, Turkey

Email address:

gulayozkann@gmail.com (G. Özkan)

To cite this article:

Gülay Özkan, Seda Ersus Bilek. Microencapsulation of Natural Food Colourants. International Journal of Nutrition and Food Sciences. Vol. 3, No. 3, 2014, pp. 145-156. doi: 10.11648/j.jinfs.20140303.13

\begin{abstract}
Carotenoids, anthocyanins, and chlorophylls are used as natural food colourants in the food industry. Microencapsulation is a technology that is used for the protection, stabilization, and the slow release of core materials. There are several techniques and wall materials that are available for microencapsulation of natural food colourants to overcome their instability, solubility, and handling problems. The objective of this paper is to describe techniques for preparation of microcapsulated food colourants and to provide a literature review of utilizable wall materials for natural colourants. Additionally, process conditions for given microencapsulation techniques are also summarized.
\end{abstract}

Keywords: Microencapsulation, Natural Food Colourant, Wall Material, Carotenoid, Anthocyanin, Chlorophyll

\section{Introduction}

\subsection{Food Colourants}

Colour is one of the most important visual attributes of food materials [1]. Interest in the development of food colourants from natural sources as alternatives to synthetic dyes has increased because of legislative action and consumer concern [2]. Food colourants are usually classified as either natural (or nature-identical) or synthetic. Natural colourants are generally more sensitive to light, temperature, $\mathrm{pH}$, and redox agents [3]. In the last 20 years synthetic colourants have been increasingly perceived as undesirable or harmful by consumers [4]. Hence, most countries have limited the use of synthetic colourants [5]. Because of these reasons, the interest in the development of food colourants from natural sources has increased [6, 7].

In our daily diets we consume large quantities of many pigments, especially carotenoids, anthocyanins, and chlorophylls [4]. One of the most consumed carotenoid groups of pigments are responsible for the yellow, orange, and red colour of many foods, continue to be intensely investigated mainly because of their health-promoting effects. These compounds possess biological functions in animals and humans against major disorders like cancer, cardiovascular diseases, cataract, arteriosclerosis, macular degeneration, and other age related diseases [8, 9, 10]. Furthermore, the carotenoids scavenge oxygen radicals and reduce oxidative stress. Thus, they indicate antioxidant activity. The carotenoids are used in food, nutraceutical, and pharmaceutical preparations by their applications as colourants and their provitamin A activity [11, 12]. Carotenoids are unstable when they're exposed to light or oxygen because of their properties as highly conjugated and intensely coloured isoprenoid plant compounds [9, 13, 14].

Another group of pigments are anthocyanins belonging to the flavonoid group, which form a group of pigments responsible for the red, purple, and blue colours [15] and have a high potential as colourants because of their low toxicity [16]. Anthocyanins possess attributes known as antioxidant, antimicrobial, anti-carcinogenic activities, neuroprotective effects $[17,18,19,20]$, and antiinflammatory activities [21]. Factors which affect the colour and stability of anthocyanins are $\mathrm{pH}$, metal ions, exposure to light, temperature, oxygen, and enzymatic activities [22].

Also there is demand for the green colour from chlorophyll and is highly desired in the food industry [23]. Chlorophyll in natural sources is in an unsuitable form for use as a colourant because of its rapid degradation. It is rapidly degraded by enzymatic reaction or other factors such as acid, oxygen, light, and heat, resulting in chlorophyll derivatives such as pheophytin, pheophorbide, pyropheophytin, and pyropheophorbide [24].

All groups of natural pigments have stability problems when extracted from their sources. Natural colors such as annatto, $\beta$-carotene, and turmeric present solubility problems during their use and may create dust clouds [25]. Encapsulated natural colors such as carotenoids, anthocyanins, and chlorophylls are easier to handle and offer 
improved stability to oxidation and solubility. It is also possible to improve dispersibility of pigments in water by encapsulation in a protein-carbonhydrate matrix. A promising technology for the conservation and the increase in the shelf life of compounds is microencapsulation; defined as the packaging of solid, liquid, and gaseous material in sealed capsules of sizes between nanometers and millimeters. The packaged material is called active or core material, and the packaging material is called the shell, wall material, carrier, or encapsulant [26]. Microencapsulation allows the creation of a physical barrier between the core and the wall materials [27]. The packaging isolates and protects the material from ambient conditions such as light, temperature, oxygen, humidity, and from interaction with other substances. If desired, the material can be released from the capsules in a controlled way and under specific conditions [28, 29, 30]. Microencapsulation provides the means of converting liquids to solids, of altering colloidal and surface properties, of providing environmental protection, and of controlling the release characteristics or availability of coated materials [31].

\section{Microencapsulation Techniques Applied to Natural Food Colourants}

There are some techniques that are mainly used for microencapsulation of colourants by wall materials are spray-drying, freeze-drying, coacervation, and emulsion among which, spray-drying has been widely used in the food industry, in addition to the pharmaceutical and biochemical industries. There are several reviews about the detailed principles of these microencapsulation techniques [30-35]. For encapsulation purposes, the core material is homogenized within the wall materials in a suitable solvent. The homogenized mixture is then fed into a spray dryer and atomized with a nozzle or spinning wheel. Water is evaporated by the hot air contacting the atomized material. The capsules are then precipitated to the bottom of the collector [36]. The major advantage of spray drying is its general applicability to both hydrophilic and hydrophobic polymer solutions. The other advantages is the ability to handle labile materials because of the short contact time in the dryer, in addition, the operation is economical. In modern spray dryers the viscosity of the solutions to be sprayed can be as high as $300 \mathrm{mPa} . \mathrm{s}$ [31]. Besides that, this technique is simple, relatively inexpensive, rapid, and hence widely used in food industry. Disadvantages of this technique are loss of a significant amount of the product due to a sticking problem through the wall of the drying chamber and the possibility of degradation of sensitive products at high drying temperatures [37]. Other limitation of the spray-drying technology is the limited number of wall materials available [38]. Due to the wrong selection of wall materials fiber formation can be another major problem in spray drying [39]. The most common materials used for microencapsulation by spray-drying are gums, like gum arabic, low molecular weight carbohydrates like maltodextrins and saccharose, cellulose, gelatine, lipids, and proteins, like soy proteins [40, 41, 42, 43, 44]. The important factor for a successful microencapsulation by spray-drying is a high solubility of the core material in solvent and a low viscosity at high solid content [37].

Another encapsulation technique is freeze-drying, which is also known as lyophilization, is one of the most useful processes for drying thermosensitive substances that are unstable in aqueous solutions [45]. This process works by freezing the material and then reducing the surrounding pressure and adding enough heat, to allow the frozen water in the material to sublimate directly from the solid phase to the gas phase [46]. Freeze-drying is a simple technique for encapsulating water-soluble essences and natural aromas, as well as drugs [38]. However this drying technique is less attractive than others because the cost of freeze drying is 50 times higher than spray drying [47], the storage and transport of particles produced is extremely expensive [48], and also the commercial applicability is severely restricted by a long processing time [49].

Microencapsulation by coacervation is the phase separation of one or more hydrocolloids from the initial solution from the effect of change in the $\mathrm{pH}$ or temperature, addition of a non-solvent or electrolyte compound, and the subsequent deposition of the newly formed coacervate phase around the active ingredient suspended or emulsified in the same reaction media [50]. Coacervation proceeds along three main steps under constant agitation:

Step1. Three immiscible phases occur in the solution. These phases includes; the core material [active ingredient], coating material, and solvent.

Step2. Adsorption of the coacervate around the core material and the liquid coating engulfs the core material by mixing the coating phase with the solvent phase.

Step3. The coating is solidified or rigidized thermally or by desolvation [51].

Induced by

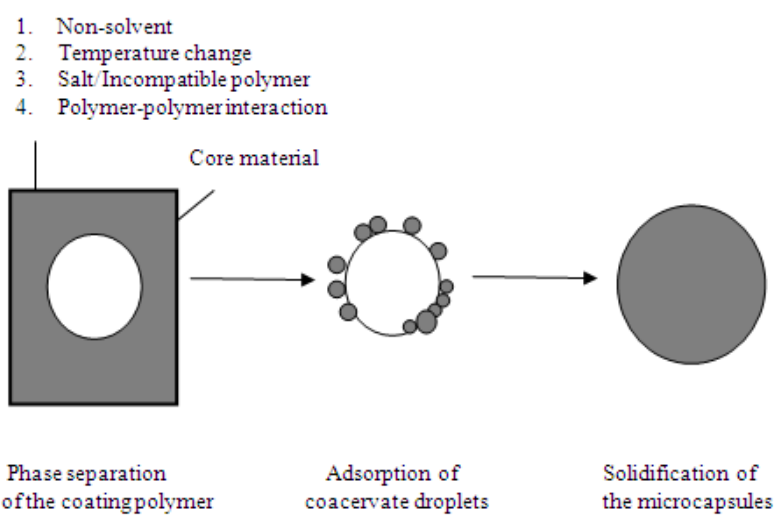

Schematic diagram of the formation of a coacervate microcapsule (52)

Coacervation can be simple or complex. Simple coacervation involves only one type of polymer with the addition of strong hydrophilic agents to the colloidal solution. Complex coacervation is produced by mixing two 
or more types of polymers for wall formation around an active core [53]. Briefly, in this technique, the core material will be added to the solution. The core material should not react or dissolve in water (maximum solubility $2 \%$ ). The core material is dispersed in the solution. The particle size will be defined by a dispersion parameter, such as stirring speed, stirrer shape, surface tension, and viscosity. The size range can change from $2 \mu \mathrm{m}-1200 \mu \mathrm{m}$. Coacervation starts with the change of the $\mathrm{pH}$ value of the dispersion, e.g. by adding $\mathrm{H}_{2} \mathrm{SO}_{4}, \mathrm{HCl}$, or organic acids. The result is a reduction of the solubility of the dispersed phases (shell material) [31]. A large numbers of wall materials have been evaluated for coacervation microencapsulation but the most studied and well understood coating system is probably the gelatin/gum acacia system. Other coating systems such as gliadin, heparin/gelatin, carrageenan, chitosan, soy protein, polyvinyl alcohol, gelatin/carboxymethylcellulose, $\beta$ lactoglobulin/gum acacia, and guar gum/dextran were also studied [50]. The gelatin based coacervation technique is well described by the Dodge Company in the USA. In this process, firstly the gelatin is dissolved in water forming a 'solution'. The solution is then heated to solubilize the gelatin. A liquid or solid core is then stirred in at a rate which will produce the desired droplet size and/or the proper dispersion. The dispersion is then treated by one of a number of means so as to cause the gelatin to come out of solution in a highly swollen, solvated state. Further treatment of our slurry causes the liquidus gelatin "coacervate" to deposit around the core material. The formed capsules can then be treated to harden the gelatin walls [54]. This technique is mostly preferred in flavors microencapsulation.

Another encapsulation technique is emulsion technology, generally applied for the encapsulation of bioactives in aqueous solutions, which can either be used directly in the liquid state or can be dried to form powders after emulsification. Basically, an emulsion consists of at least two immiscible liquids, usually as oil and water, with one of the liquids being dispersed as small spherical droplets in the other [55]. A system that consists of oil droplets dispersed in an aqueous phase is called an oil-in-water $(\mathrm{o} / \mathrm{w})$ emulsion, whereas, a system that consists of water droplets dispersed in an oil phase is called a water-in-oil (w/o) emulsion. With the exception of the simple $\mathrm{o} / \mathrm{w}$ or $\mathrm{w} / \mathrm{o}$ systems, various types of multiple emulsions can be developed, such as oil-in-water-in-oil (o/w/o) or water-inoil-in-water (w/o/w) emulsions [56, 57]. Betz and Kulozik [58] obtained microcapsules with the emulsion method which includes the generation of a w/o emulsion with a whey protein solution and bilberry anthocyanins. Furthermore, aspartame was microencapsulated by double emulsion followed by the complex coacervation method. The water-in-oil (w/o) primary emulsion was prepared using soybean oil and aspartame with a homogenizer. Then, the primary emulsion was emulsified in gelatin and gum arabic solutions to obtain a double water-in-oil-in-water (w/o/w) emulsion [59]. Additionally, Lee and Rosenberg
[60] studied whey protein based anhydrous milk fat microcapsules. A double emulsion was obtained in two steps which consisted of preparing a primary $(\mathrm{o} / \mathrm{w})$ emulsion by dispersing the anhydrous milk fat in the whey protein wall-solution and then preparing an oil-in-water-inoil (o/w/o) double emulsion in which the o/w emulsion was dispersed in corn oil. The emulsion formation determines the resulting particle size by applying mechanical energy which deforms the interface between the two phases to such an extent that droplets form. These droplets are typically large and are subsequently disrupted or broken up into smaller ones. The ability to disrupt the larger droplets is a critical step in emulsification and in encapsulation where an emulsion is prepared. When dyes are considered as the main encapsulate the problems involved, at this stage, can be minor because most dyes are quite stable [61].

\section{Wall Materials Used in Microencapsulation of Natural Food Colourants}

Numerous wall materials or encapsulating agents are available for food application. The ideal encapsulant generally should have film-forming properties, have emulsifying properties, be biodegradable, be resistant to the gastrointestinal tract, have a low viscosity at high solids contents, exhibit low hygroscopicity, and have a low cost [62].

Maltodextrins of different dextrose equivalent (DE), modified starches, gums arabic, and some proteins are the most commonly used as wall materials [25]. Maltodextrins that are a nonsweet nutritive polysaccharides consisting of $\alpha-(1-4)$ linked D-glucose, are obtained by partial acid hydrolysis of several starches [corn, potato or others] and they exhibit high water solubility, low viscosity, bland flavor, and form colourless solutions [36, 63]. Maltodextrins are available in different molecular weights which provide different wall densities around the sensitive materials [47, 64, 65]. Maltodextrins with degrees of dextrose equivalence (DE) between 10 and 20 are widely used in the encapsulation of anthocyanins and phenolic acids [66, 67]. The product with the highest DE is extremely stable in protecting encapsulated ingredients from oxidation [25]. Problems associated with the use of hydrolyzed starches in microencapsulation are lack of emulsification properties and poor flavor retention [68].

Another common material for microencapsulation is modified starch, modified by the addition of a lipophylic component, octenylsuccinate, which increases the emulsion stability [69]. $n$-octenylsuccinate-derivatised starch is used by the food and pharmaceutical industry with approval of the FDA (Food and Drug Administration) as a food additive since the content of octenylsuccinate does not exceed $3 \%$ [70]. Modified starch has the ability to produce small particle size droplets to promote emulsion stability [25].

Cyclodextrins are cyclic molecules derived enzymatically from starch and have the ability to 
encapsulate active material within their ring structure. Bcyclodextrins have both a hydrophilic and hydrophobic nature which leads to noncovalently interactions with suitable core materials to form stable complexes [25]. Natural pigments such as carotenoids and flavonoids can be encapsulated within cyclodextrins to form complexes which protects the ingredients from oxidation, light induced reactions, and thermal decompositions [71].

Gum arabic is one of the most important carriers and a wall material used for flavors and colourants [72] and is still a good choice as a wall material due to its stable emulsion and good volatile retention. Gum arabic can be used alone or combined with other encapsulants in the production of powder from pigment extracts $[62,67$, and 73]. However, several problems are associated with the use of this gum for microencapsulation, including its high cost and limited supply [53].

Another possible encapsulation agent may be inulin [74]. Inulin is a fructooligosaccharide (FOS) obtained commercially from chicory (Cichorium intybu) root, Dahlia (Dahlia pinnata), and Jerusalem artichoke (Helianthus tuberosus). The inulin is composed of fructose units with $\beta$ (2-1) links with glucose at the end of the chain. Inulin shows prebiotic effects and dietary fiber action and improves calcium bioavailability [74, 75]. Inulin is only hydrolysed in small amounts in the stomach and the large intestine without the formation of monosaccharide's; it is fermented by the large intestinal microflora into short chain fatty acids and butyrate which is the major fermentation product of inulin, whereas, lactate and acetate mostly occurs. Therefore, there is no resultant increase to the glycemic index, which is important as a potential ingredient for diabetic foods [74].

Gelatin is a soluble protein compound obtained by partial hydrolysis of collagen [76]. Gelatin as a wall material is a good choice due to its good properties of emulsification, film-formation, water-solubility, edibility, and biodegradation [77].

Furcellaran is an anionic sulphated polysaccharide extracted from red algae Furcellaria lumbricalis. Furcellaran is a copolymer of $\beta$ - and $\kappa$-carrageenan [78] and is usually represented as a structurally repeating unit of alternating 3-linked $\beta$-d-galactopyranose and 4-linked $\alpha$-dgalactopyranose residues, with a part of the latter existing as a 3,6-anhydro derivative [79]. Being a nontoxic, biodegradable, and biocompatible polysaccharide, furcellaran is a very promising biomaterial for encapsulation [14].

Chitosan, a linear heteropolysaccharide derivative from chitin by $N$-deacetylation, has various bioactivities which include antifungal, antibacterial, antitumor, antiallergic, antioxidant, immune system activating, anti-hypertensive, and cholesterol lowering properties, besides being from a natural source, biologically reproducible, almost non-toxic, biocompatible, and biodegradable. These factors have encouraged the application of chitosan in many fields [80, 81, and 82]. Chitosan has great potential applications in the pharmaceutical industry as a lipophilic encapsulation for drugs [83] and in the food industry as an encapsulation for probiotics and prebiotics [84], aromatic compounds [85], enzymes [86], and antioxidants [87].

Another important group of wall materials are proteins that can be used as a reasonable alternative matrix material because of their highly concentrated solutions $(>10 \%)$ and their low viscosity. Whey proteins of these are available as whey protein isolate (WPI) or whey protein concentrate (WPC) powders. Whey protein concentrate (WPC) and isolate (WPI) have been shown to exhibit excellent microencapsulating properties for both volatile and nonvolatile core materials [88].

\section{Wall Materials and Process Conditions in Natural Colourants Microencapsulation}

In the food industry, different wall materials and methods are used for microencapsulation of natural pigments as food colourants. Microencapsulation techniques and wall materials applied to natural food colourants are given in Table 1. Studies on different groups of pigments such as carotenoids, anthocyanins, and chlorophylls, in addition to other minor pigments were summarized and evaluated in sections. The stability and handling problems of natural colourants were overcome by using microencapsulation techniques. The approach to choosing wall materials and microencapsulation techniques changed according to the commercial usage of the natural colourants and suitability for the different food industries and food materials and the pharmaceutical industry.

Table 1. Microencapsulation techniques and wall materials applied to the natural food colourants

\begin{tabular}{|c|c|c|c|}
\hline Food Colourants & Wall materials & Microencapsulation techniques & References \\
\hline Anthocyanin & Maltodextrins & Spray drying & Ersus and Yurdagel, 2007 \\
\hline Anthocyanin & Mesquite gum & Spray drying & Jimenez-Aguilar et al., 2011 \\
\hline Anthocyanin & $\begin{array}{l}\text { Maltodextrins } \\
\text { Inulin }\end{array}$ & Spray drying & Bakowska-Barczak and Kolodziejczyk, 2011 \\
\hline Anthocyanin & $\begin{array}{l}\text { Whey protein } \\
\text { Maltodextrin }\end{array}$ & Emulsion method & Betz and Kulazik, 2011 \\
\hline Anthocyanin & $\begin{array}{c}\text { Gum arabic } \\
\text { Modified starch }\end{array}$ & Spray drying & Ibrahim Silva et al., 2013 \\
\hline Anthocyanin & $\begin{array}{l}\text { Maltodextrins } \\
\text { Gum arabic } \\
\text { Tapioca starch }\end{array}$ & Spray drying & Tonon et al., 2010 \\
\hline
\end{tabular}




\begin{tabular}{|c|c|c|c|}
\hline Food Colourants & Wall materials & Microencapsulation techniques & References \\
\hline Astaxanthin & $\begin{array}{l}\text { Chitosan } \\
\text { Gum arabic }\end{array}$ & Multiple emulsion / solvent evaporation & Higuera-Ciapara et al., 2004 \\
\hline Astaxantin-oleoresin & $\begin{array}{l}\text { Whey protein } \\
\text { Maltodextrin } \\
\text { Inulin }\end{array}$ & Spray drying & Bustos-Garza et al., 2013 \\
\hline Betacyanin & $\begin{array}{l}\text { Glucose } \\
\text { Maltodextrin }\end{array}$ & Spray drying & Obon et al., 2009 \\
\hline Betacyanin & $\begin{array}{l}\text { Native starch } \\
\text { Modified starch }\end{array}$ & Spray drying & Cai and Corke, 2000 \\
\hline Betacyanin & Gum arabic & Spray drying & Pitalua et al., 2010 \\
\hline Betacyanin & Maltodextrin & Spray drying & Azeredo et al., 2007 \\
\hline Betalain & Maltodextrin & Spray drying & Janiszewska and Wlodarczyk, 2013 \\
\hline Bixin & $\begin{array}{l}\text { Gum Arabic } \\
\text { Maltodextrin } \\
\text { Gum arabic }\end{array}$ & Spray drying & Barbosa et al., 2005 \\
\hline Chlorophyll & $\begin{array}{c}\text { Maltodextrin } \\
\text { Osa-modified starch }\end{array}$ & Spray drying & Porrarud and Pranee, 2010 \\
\hline Lycopene & Modified starch & Spray drying & Rocha et al., 2012 \\
\hline Lycopene & $\begin{array}{l}\text { Gelatin } \\
\text { Sucrose }\end{array}$ & Spray drying & Shu et al., 2006 \\
\hline Oleoresin & $\begin{array}{l}\text { Gum arabic } \\
\text { Soy protein }\end{array}$ & Spray drying & Rascon et al., 2011 \\
\hline$\beta$-carotene & $\begin{array}{l}\text { Modified tapioca starch } \\
\text { Native tapioca starch } \\
\text { Maltodextrin }\end{array}$ & Spray drying & Loksuwan, 2007 \\
\hline$\beta$-carotene & $\begin{array}{c}\text { Native and hydrolyzed Pinhão } \\
\text { starches }\end{array}$ & Freeze-drying & Corralo Spada et al., 2012 \\
\hline$\beta$-carotene & Furcellaran & Ionotropic gelation & Laos et al., 2007 \\
\hline Turmeric & Polyvinylpyrrolidone & Spray drying & Martins et al., 2010 \\
\hline Saffron & $\begin{array}{l}\text { Gum Arabic } \\
\text { Maltodextrin }\end{array}$ & Freeze drying & Mahdavee Khazaei et al., 2014 \\
\hline Saffron & $\begin{array}{l}\text { Pullulan } \\
\text { Polyvinylpyrrolidone }\end{array}$ & Freeze drying & Selim et al., 2010 \\
\hline
\end{tabular}

\section{Microencapsulation of Carotenoids}

There are some experiments for testing the stability of the wall materials used in the microencapsulation of $\beta$-carotene. It has been reported that hydrolyzed starches show the highest efficiencies in $\beta$-carotene retention. Acid modified tapioca starch, native tapioca starch, and maltodextrin were used as wall materials for $\beta$-carotene microencapsulation. Microcapsules were prepared by spray drying. The ability of acid modified tapioca starch, native tapioca starch, and maltodextrin were tested to serve as wall materials. The results obtained suggest that the modified tapioca starch can be considered as a potential wall material for encapsulation of $\beta$-carotene [89]. Nevertheless, Corralo Spada et al. [90] showed that microcapsules encapsulated by the freeze-drying method with 12 dextrose equivalent (DE) hydrolyzed starch exhibited the highest stability. In contrast, microcapsules prepared with native starch showed the lowest stability during storage.

Furcellaran as a wall material was used to evaluate the microencapsulation process of $\beta$-carotene from sea buckthorn (Hippophaë rhamnoides L.) juice. Encapsulation efficiency, which is the amount of $\beta$-carotene encapsulated with respect to the initial amount of $\beta$-carotene taken in by the furcellaran capsules, was found to be $97 \%$. With the increasing proportion of sea buckthorn juice in the formulae, the firmness of the furcellaran beads decreased. It is suggested that furcellaran beads may be used for $\beta$ carotene encapsulation [14].

Modified starch could be used as a wall material in the microencapsulation process of lycopene. Spray drying was used as encapsulation method to evaluate the conditions of this process. The quantity of lycopene was varied at 5,10 , and $15 \%$ in a solution containing $30 \%$ solids in order to obtain the microcapsules. According to the results, encapsulation efficiency increased as the quantity of lycopene decreased. Besides, retention of microencapsulated lycopene was significantly greater when kept at $10^{\circ} \mathrm{C}$ compared to storage at $25^{\circ} \mathrm{C}$ [91]. There are different studies about different wall materials used for microencapsulation of lycopene. Shu et al. [92] made lycopene capsules using a wall system consisting of gelatin and sucrose by spray drying. The optimal condition was determined as the ratio of gelatin/sucrose of $3 / 7$ and the ratio of core and wall material of $1 / 4$, feed temperature of $55^{\circ} \mathrm{C}$, inlet temperature of $190^{\circ}$ $\mathrm{C}$, homogenization pressure of $40 \mathrm{MPa}$, and lycopene purity of not less than $52 \%$.

Synthetic astaxanthin was microencapsulated in a chitosan matrix by using the method of multiple emulsion/solvent evaporation. The stability of the pigment in the microcapsules was studied when stored at 25,35 , and $45^{\circ} \mathrm{C}$ for 8 weeks. Results showed that the microencapsulated pigment did not allow chemical 
degradation nor isomerization under the investigated storage conditions [93]. Generally, carotenoids are found in nature as all-trans molecules in which all the double bonds are in the Trans configuration [94]. High temperature and light conditions may promote the isomerization to the $\mathrm{Cis}$ forms. The Cis isomers of the provitamin A carotenoids have less activity than their corresponding all-trans carotenoids [95]. The microencapsulation process is performed in order to protect the biological activity of astaxanthin from environmental factors and enhance its physicochemical stability.

Paprika oleoresin which has two isochromatic fractions as red (diesterified capsanthin and capsorubin) and yellow ( $\beta$-carotene, esterified cryptoxanthin and diesterified zeaxanthin) have also been studied in microencapsulation as a core material [96]. Gum arabic and soy protein isolate were used as a wall material in the spray drying method. Achievement of gum arabic and soy protein isolate in the microencapsulation of paprika oleoresin and their storage was evaluated. All treatments showed that carotenoid retention in the microcapsules increased as the inlet air temperature was increased from 160 to $200^{\circ} \mathrm{C}$ and the yellow fraction was more stable than the red fraction at all temperatures tested [97].

Astaxantin oleoresin was microencapsulated by spray drying using various wall materials such as gum arabic, whey protein, maltodextrin, and inulin. Whey protein alone or combined with gum arabic presented the best encapsulation yield (61.2-70.1\%) instead of the gum arabic, gum arabic-maltodextrin, gum arabic-inulin, whey proteinmaltodextrin, and whey protein-inulin [98].

Bixin, which is an apo-carotenoid, was encapsulated by spray drying with wall material with either gum arabic or maltodextrin and the light stability was then evaluated. As a result, bixin encapsulated with gum arabic was 3 to 4 times more stable than that encapsulated with maltodextrin [99].

Modified starches could be used in microencapsulation of $\beta$-carotene by spray drying or freeze drying methods. In addition, they can be used for lycopene encapsulation. Modified starches provide more effective retention instead of in their native form. Moreover, furcellaran and chitosan are encouraging biomaterial that can be applied for the encapsulation process. Numerous wall materials are available for food application such as whey protein, gelatin, sucrose, gum arabic, and soy protein. Additionally, according to the results, carotenoid retention in the microcapsules increased as the inlet air temperature increased.

\section{Microencapsulation of Anthocyanins}

Literature about the ability of wall materials that are used in the microencapsulation of anthocyanins were evaluated, where different dextrose equivalents of maltodextrins (10DE, 20-23DE, and 28-31DE) were used as wall materials for microencapsulation of black carrot anthocyanin pigments. Microcapsules were prepared by the spray drying method. As a wall material 20-23DE maltodextrin gave the highest anthocyanin content powder at the end of drying process [66]. Whereas, Tonon et al. [100] found that maltodextrin 10DE was the carrier agent that showed the best pigment protection and the highest antioxidant activity instead of maltodextrin 20DE, gum arabic, and tapioca starch in the microencapsulation of açai anthocyanins using the spray drying method. Additionally, samples were stored at different temperatures $\left(25\right.$ and $\left.35^{\circ} \mathrm{C}\right)$ and water activities $(0.328$ and 0.529$)$, in order to investigate the effect of storage conditions on the antioxidant activity reduction. Antioxidant activity decreased with increasing water activity and storing at higher temperatures caused lower antioxidant activity. Nonetheless, there is another study to examine the combination of carrier agents. Ibrahim Silva et al. [101] evaluated different combinations of wall materials maltodextrin, gum arabic/maltodextrin, and modified starch/maltodextrin in the microencapsulation process. The results showed that the use of $30 \%$ maltodextrin as a carrier agent gave the optimum results in spray drying. Moreover, the use of maltodextrin and arabic gum allowed for the formation of more homogeneous particles.

There is limited information about the use of protein hydrogels as matrix materials for microencapsulation of anthocyanin pigments. Betz and Kulozik [58] investigated the effects of the production conditions of the emulsifier addition in the emulsion/heat gelation method. Results showed that when no emulsifier or the emulsifier Span 80 was used, aggregated and coalesced microcapsules were obtained; only PCDL was effective in stabilizing the emulsion droplets during gelation with the mean diameters below $70 \mu \mathrm{m}$ which is practicable for food applications.

Process conditions of the microencapsulation of anthocyanins were also investigated in different studies. Jimenez-Aguilar et al. [102] found that, the lowest losses in the content of total phenolics, total anthocyanins, and colour of the microcapsules was found at $140^{\circ} \mathrm{C}$ of air inlet temperature instead of $160^{\circ} \mathrm{C}$ of air inlet temperature. Ersus and Yurdagel [66] confirmed this finding that higher inlet/outlet temperatures caused greater anthocyanin loss during spray drying. The optimum drying temperature was found as $160^{\circ} \mathrm{C}$ instead of $180^{\circ} \mathrm{C}$ or $200^{\circ} \mathrm{C}$. In addition, storage at $4^{\circ} \mathrm{C}$ increased the half life of the spray dried anthocyanin pigments 3 times (according to or when compared to the) $25^{\circ} \mathrm{C}$ storage temperature. On the other hand, Ibrahim Silva et al. [101] applied three different air drying temperatures of 140,160 , and $180^{\circ} \mathrm{C}$. According to the results maltodextrin and the air drying temperature of $180^{\circ} \mathrm{C}$ was selected as the optimum condition with the highest desirability (0.7-0.8).

All of these studies showed that maltodextrin is a suitable carrier agent used in microencapsulation of anthocyanins by spray drying. Higher air inlet temperatures in spray drying caused a higher loss of the anthocyanin. As a result, optimum conditions should be investigated for each core and wall material and encapsulation method for 
minimizing the losses of anthocyanins.

\section{Microencapsulation of Chlorophylls}

There is very limited research in literature about the microencapsulation of chlorophyll. Zn-chlorophyll derivatives were microencapsulated by spray drying. Three different wall materials such as gum arabic, maltodextrin, and octenyl succinic anhydride (osa)-modified starch was studied. At 30\% osa-modified starch as a wall material, the highest greenness value, total chlorophyll, and antioxidant activity were obtained for Zn-chlorophyll powder. Additionally, osa-modified starch powder provided a longer half life for microcapsulated chlorophyll than gum arabic and maltodextrin powders [103].

\section{Microencapsulation of Other Colourants}

Betalains are classified as red-violet betacyanins and yellow-orange betaxanthins [104]. The stability of betalains is influenced by numerous factors such as temperature, metals, $\mathrm{pH}$, water activity, light exposure, enzymes, and oxygen [105]. The stability has an important effect for using these pigments as antioxidants and colourants in foods [106]. There are some experiments about analyzing the stability of betalain microcapsules and evaluating the wall materials and encapsulation methods that are used in the microencapsulation process. The antioxidative activity of microencapsules which are obtained from beetroot betalains was evaluated throughout storage at different water activities. The powder stored at $\mathrm{a}_{\mathrm{w}}<0,521$ presented the highest stability [73]. Janiszewska and Wlodarczyk [107] evaluated the effect of inlet air temperature which varied from 120 to $160^{\circ} \mathrm{C}$. Low-crystallized maltodextrin $(\mathrm{DE}=11)$ was used as a wall material for the microencapsulation of beetroot betalains by the spray drying method. It was observed that the increase of inlet air temperature caused a decrease in the yellow pigment to a higher degree $(47 \%)$ than in the violet pigment $(17 \%)$. Furthermore, betacyanin extracts were spray dried using a range of maltodextrins $(10-25 \mathrm{DE})$ and starches (native/modified) as a drying agent. The higher inlet temperature caused higher betacyanin loss during spray drying [65]. Whereas Obón et al. [108] found that drying yield, colour yield, and colour strength increased when the temperature was increased. Glucose syrup [ $\mathrm{DE}=29]$ was used as drying aid for microencapsulation of betacyanin pigment. Three different inlet air temperatures were evaluated in this process and the optimum condition was found as $160^{\circ} \mathrm{C}$ for the inlet air temperature. Pigment retention during processing and storage of microencapsulated betacyanins was also investigated. Red beetroot extracts were encapsulated by spray drying. The pigment retention of the powders was found at $90 \%$ for each maltodextrin. The beetroot ratios were $3: 1,4: 1$, and
$5: 1$. The result of Betacyanin degradation in dark jars was around $30 \%$ and in translucent jars around $57 \%$ after the same storage time [109].

Another food colourant is turmeric extract which presents the principal colour in the rhizome of the turmeric plant [Curcumin longa]. There are three main types of turmeric extract; essential oil of turmeric, turmeric oleoresin, and curcumin [104]. The rhizomes of Curcumin longa are used as an important natural yellow colourant in foods [110], and they have numerous biological activities as antioxidant, antimicrobial, anti-tumor, anti-inflammatory, anti-virus, and anti-HIV [111]. Nevertheless, free curcumin is water-insoluble and is susceptible to breakdown by oxidants [light and heat] [112]. The microencapsulation technique was used to overcome these problems and improve the solubility and stability of curcumin. After microencapsulation, curcumin microcapsules would instantly dissolve in water [113]. Martins et al. [114] evaluated the effects of spray drying on the curcumin content, antioxidant activity, and solubility of the microparticulated solids. Increasing of the outlet temperature from 40 to $80{ }^{\circ} \mathrm{C}$ resulted in an increase in curcumin content ( 3.24 to $4.25 \mathrm{mg} / \mathrm{g})$ and antioxidant activity ( 530.1 to $860.3 \mu \mathrm{g} / \mathrm{mL})$. Moreover, the solubility of curcuminoid from Curcumin longa improved 100-fold in the microparticles using the spray drying process.

Saffron is obtained from the red dried stigmas of the flowers of the Crocus sativus L. [115], and has oxytocic, anti-carcinogenic, exhilarant, anti-depressant, and antiasthma effects [116]. Saffron, the product of commerce, consists of the dried red stigmas, rich in the carotenoid secondary metabolite crocetin, and derivatives crocin (colour), picrocrocine (flavor), and safranal (aroma) [117]. It is typically used as a spice with colouring properties in culinary, bakery, alcoholic, and non alcoholic beverages [118]. The colour stability of encapsulated freeze-dried saffron extract with various wall materials consisting of gum arabic and maltodextrin $(\mathrm{DE}=7$ and $\mathrm{DE}=20)$ were evaluated. The lowest total colour difference after storage was obtained with maltodextrin ( $\mathrm{DE}=7$ and $\mathrm{DE}=20)$; moreover the highest total colour difference was obtained with gum arabic [119]. Selim et al. [120] investigated the degradation kinetics of saffron water soluble carotenoids encapsulated with 3 different wall materials (pullulan, polyvinylpyrolidone 40, and polyvinylpyrolidone 360) using the freeze-drying method. Experimentation was carried out under different water activity conditions $(0.43 ; 0.53 ; 0.64$, and 0.75$)$. It was found that polyvinylpyrolidone 40 was the most effective wall material under all storage conditions.

Carmine is used to describe the aluminum chelate of carminic acid which is the colour extracted from the dried female coccid insect. Cochineal is used to describe both the dried insects themselves and colour derived from them. Coccid insects of many species have been used for thousands of years as a source of red colour [104]. There is no research which evaluates the process conditions or storage stability of carmine in microencapsulation. 


\section{Food Applications of Microencapsulated Colourants}

Microencapsulated colourants can be used commercially as a food dye. Possible food materials could be yogurt, icecream, sweets, glace cherries, and other confectionary products. In addition, chewing gums, snack foods, and products for children are the major food products that require natural colourants. Bakery products such as biscuits are also in a group of food materials that requires colouring considerably. In literature, food applications of microencapsulated natural colourants had been investigated in several studies (Table 2). Rocha et al. [91] used lycopene microcapsules in cake. Moreover, yogurt, soft drink, and jam syrup were used as a food model system for anthocyanin [121] and betacyanin microcapsules [108].

Table 2. Food applications of microencapsules.

\begin{tabular}{lll}
\hline Core material/wall material & $\begin{array}{l}\text { Food model } \\
\text { systmes }\end{array}$ & References \\
\hline Anthocyanin/maltodextrin & $\begin{array}{l}\text { Yogurt and soft } \\
\text { drink }\end{array}$ & Ersus, 2004 \\
$\begin{array}{l}\text { Red Beetroot } \\
\text { extract/maltodextrin }\end{array}$ & Yogurt & $\begin{array}{l}\text { Azeredo et al., } \\
2007\end{array}$ \\
Betacyanin/glucose syrup & $\begin{array}{l}\text { Yogurt and soft } \\
\text { drink }\end{array}$ & Obon et al., 2008 \\
Lycopene/modified starch & cake & $\begin{array}{l}\text { Rocha et al., } \\
2012\end{array}$ \\
\hline
\end{tabular}

\section{Conclusion}

The use of natural food colourants exhibits a positive effect on the consumer demand for natural products and microencapsulation is a method that can potentially protect natural colourant from degradation. Several studies have proved the ability of various wall materials to protect stability of active materials as food colourants, using different microencapsulation methods by packaging an active ingredient inside a capsule ranging in size from one micron to several millimeters. The capsule protects the active ingredient from its surrounding environment conditions such as humidity, light, oxygen or heat. until an appropriate time. Optimum process conditions for the encapsulation techniques should be achieved for each active and wall material. Encapsulation technique for minimizing the losses of pigment retention should be aimed for each process for effectual design and development of the desired microcapsule properties. An analysis of scientific articles show limited understanding about comparison of methods used in microencapsulation of natural colourants. Most of the studies are based on similar wall materials for similar natural colourants type. Maltodextrins and spray drying turned out to be essential to preserve the integrity of the water soluble pigments where modified starch is the best for oil soluble pigments.

\section{References}

[1] Maskan M (2001) Kinetics of colour changes of kiwifruits during hot air a microwave drying. Journal of Food Engineering 48:169-175

[2] Giusti MM (1996) Radish anthocyanin extract as a natural red colorant for maraschino cherries. Journal of food science 61(4):688-694

[3] Macrae R, Robinson R, Sadler M (1993) Encyclopaedia of Food Science, Food Technology and Nutrition. Academic Press, San Diego

[4] Downham A, Collins P (2000) Colouring our foods in the last and next millennium. International Journal of Food Science and Technology 35:5-22

[5] Ni Y, Gong X (1997) Simultaneous spectrophotometric determination. Analytica Chimica Acta 354:163-171

[6] Francis FJ (1987) Lesser-known food colorants. Food Technology 41:62-68

[7] Ilker R (1987) In-vitro pigment production: an alternative to color synthesis. Food Technology 41:70-72

[8] Krinsky N (1993) Actions of carotenoids in biological systems. Annual Review of Nutrition 13:561-589

[9] Mayne S (1996) $\beta$-carotene, carotenoids, and disease prevention in humans. Federation of American Societies for Experimental Biology Journal 10:690-701

[10] Olson J (1999) Carotenoids, Shils M, Olson J, Shike M, Ross Z. In. Modern Nutrition in Health. Baltimore, Williams \& Wilkins 525-541

[11] Rao A, Honglei S (2002) Effect of low dose lycopene intake on lycopene bioavailability and oxidative stress. Nutrition Research 22:1125-1131

[12] Young A, Lowe G (2001) Antioxidant and prooxidant properties of carotenoids. Archives of Biochemistry and Biophysics 385:20-27

[13] Ziegler RG, Mayne ST, Swanson CA (1996) Nutrition and lung cancer. Cancer Causes Control 7:157-177

[14] Laos K, Lougas T, Mandmets A, Vokk R (2007) Encapsulation of $\beta$-carotene from sea buckthorn [Hippophaë rhamnoides L.] juice in furcellaran beads. Innovative Food Science and Emerging Technologies 8:395-398

[15] Doughall DK, Baker D, Gakh E, Redus M, Whittemore N (1998) Anthocyanins from wild carrot suspension cultures acylated with supplied carboxylic acids. Carbohydrate Research 310:177-189

[16] Brouillard R (1982) Chemical structure of anthocyanins, Markasis P. Anthocyanins as food colors. Academic Press, London 1-40

[17] Han X, Shen T, Lou H (2007) Dietary polyphenols and their biological significance. International Journal of Molecular Sciences 8:950-988

[18] Ramos S (2008) Cancer chemoprevention and chemotherapy: dietary polyphenols and signalling pathways. Molecular Nutrition and Food Research 51:507-526 
[19] Soobrattee M, Bahorun T, Aruom O (2006) Chemopreventive actions of polyphenolic compounds in cancer. Biofactors 27:19-35

[20] Neto C (2007) Cranberry and blueberry: evidence for protective effects against cancer and vascular diseases. Molecular Nutrition and Food Research 51:652-664

[21] Seeram NP, Bourquin LD, Nair MG (2001) Cyclooxygenase inhibitory and antioxidant cyanidin glycosides in cherries and berries. Phytomedicine 8:362-369

[22] Bakowska M, Kucharska A, Oszmianski J (2003) The effects of heating, UV irradiation and storage on stability of anthocyanin-polyphenol copigment complex. Food Chemistry 81:349-355

[23] Senklang P, Anprung P (2010) Optimizing enzymatic extraction of $\mathrm{Zn}$-Chlorophyll derivatives from pandan leaf using response surface methodology. Journal of Food Processing and Preservation 34:759-776

[24] Humhrey A (1980) Chlorophyll. Food Chemistry 5:57-67

[25] Shahidi F, Han XQ (1993) Encapsulation of food ingredients. Critical Reviews in Food Science and Nutrition 33:501-547

[26] Green BK, Scheicher L (1955) Pressure Sensitive Record Materials. US Patent Nu. (2), 217-507, Ncr C.

[27] Dubey R, Shami T, Bhasker Rao K (2009) Microencapsulation technology and application. Defence Science Journal 59:82-95

[28] Dziezak J (1988) Microencapsulation and encapsulated ingredients. Food Technology 2:36-51

[29] Risch S (1955) Encapsulation: overview of uses and techniques. Risch S, Reineccius G. In. American Chemist's Society, Symposium Series, Washington 590: 2-7

[30] Re M (1998) Microencapsulation by spray-drying. Dry Technology 16:1195-1236

[31] Shekhar K, Madhu M, Pradeep B, Banji D (2010) A review on microencapsulation. International Journal of Pharmaceutical Sciences and Research 5(2):5862

[32] Schierle J, Bretzel W, Bühler I, Faccin N, Hess D, Steiner K (1997) Content and isomeric ratio of lycopene in food and human blood plasma. Food Chemistry 59:459-465

[33] Yeo Y, Baek N, Park K (2001) Microencapsulation Methods for Delivery of Protein Drugs. Biotechnology and Bioprocess Engineering 6:213-230

[34] Jimenez M, Garcia H, Beristain C (2004) Spray-drying microencapsulation and oxidative stability of conjugated linoleic acid. European Food Research and Technology 219:588-592

[35] Rodriguez-Huezo M, Pedroza-Islas R, Prado-Barragan L, Beristain C, Vernon-Carter E (2004) Microencapsulation by spray drying of multiple emulsions containing carotenoids. Journal of Food Science 69:351-359

[36] Gibbs B, Kermasha S, Alli I, Mulligan C (1999) Encapsulation in the food industry: a review. International Journal of Food Sciences and Nutrition 41:1521-1527

[37] Nesterenko A, Alric I, Silvestre F, Durrieu V (2013) Vegetable proteins in microencapsulation: A review of recent interventions and their effectiveness. Industrial Crops and Products 42:469-479

[38] Desai K, Park H (2005) Recent developments in microencapsulation of food ingredients. Drying Techology 23:1361-1394

[39] Bodmeier R, Chen H (1988) Preparation of biodegradable polylactide microparticles using a spray-drying technique. Journal of Pharmacology and Pharmacotherapeutics 40:754757

[40] Faldt P, Bergenstahl B (1995) Fat encapsulation in spraydried food powders. Journal of American Oil Chemists' Society $72: 171-176$

[41] Lin C, Lin S, Hwang L (1995) Microencapsulation of squid oil with hydrophilic macromolecules for oxidative and thermal stabilization. Journal of Food Science 60:36-39

[42] Kim Y, Morr C (1996) Microencapsulation properties of gum arabic and several food proteins: spray-dried orange oil emulsion particles. Journal of Agricultural and Food Chemistry 44:1314-1320

[43] Hogan S, McNamee B, O'Riordan E, O'Sullivan M (2001) Microencapsulation properties of sodium caseinate. Journal of Agriculturel and Food Chemistry 49:1934-1938

[44] Gharsallaoui A, Roudant G, Chambin O, Voilley A, Saurel R (2007) Applications of spray-drying in microencapsulation of food ingredients: a review. Food Research International 40:1107-1121

[45] Karel M, Langer R (1988) Controlled release of food additives. Risc S, Reineccius G. In; Flavour Encapsulation. American Chemical Society, Washington 177-191

[46] Oetjen G, Haseley P (2004) Freeze-Drying. Wiley-VCH Verlag $\mathrm{GmbH} \& \mathrm{Co}$ : Weinheim

[47] Desorby S, Netto F, Labuza T (1997) Comparison of spraydrying, drum-drying and freeze-drying for B-carotene encapsulation and preservation. Journal of Food Science 62:1158-1162

[48] Jacquot M, Pernetti M (2003) Spray coating and drying processes. Nedovic U, Willaert R (2003) In; Cell Immobilization Biotechnology. Kluwer Academic Publisher, Netherlands 343-356

[49] Barbosa-Canovas G, Vega-Mercado H (1996) Dehydratation of Foods. Chaman \& Hall, New York

[50] Gouin S (2004) Microencapsulation: industrial appraisal of existing technologies and trends. Trends of Food Science and Technology 15:330-347

[51] Nihant N, Grandfils C, Jerome R, Teyssie P (1995) Microencapsulation by coacervation of poly [lactide-coglycolide] IV. Effect of the processing parameters on coacervation and encapsulation. Journal of Controlled Release 35(2-3):117-125

[52] Burgess D, Hickey A (1994) Microsphere technology and applications. Swarbrick J, Boylan J. Ancyclopedia of Pharmacuetical Technology. Marcel Dekker, New York, USA 1-29

[53] Wilson N, Shah N (2007) Microencapsulation of vitamins. ASEAN Food Journal 14:1-14 
[54] Anon (2014) http://www.rtdodge.com/RTDcoacervation.html (14.01.2014)

[55] Friberg S, Larsson K, Sjoblom J (2004) Food emulsions. Marcel Dekker, New York (4)

[56] Benichou A, Aserin A, Garti N (2004) Double emulsions stabilized with hybrids of natural polymers for entrapment and slow release of active matters. Advances in Colloid and Interface Science 108-109, 29-41

[57] Van Der Graaf S, Schroen C, Boom R (2005) Preparation of double emulsions by membrane emulsification-a review. Journal of Membrane Science 251:7-15

[58] Betz M, Kulozik U (2011) Microencapsulation of bioactive bilberry anthocyanins by means of whey protein gels. Procedia Food Science 1:2047-2056

[59] Rocha-Selmi G, Bozza F, Thomazini M, Bolini H, FávaroTrindade C (2013) Microencapsulation of aspartame by double emulsion followed by complex coacervation to provide protection and prolong sweetness. Food Chemistry 139:72-78

[60] Lee S, Rosenberg M (2000) Preparation and some properties of water-insoluble, whey protein-based microcapsules. Journal of Microencapsulation 17(1):29-44

[61] Mathiowitz E, Kreitz M, Brannon-Peppas L (1999) Microencapsulation. Mathiowitz E. Ancyclopedia of Controlled Delivery. John Wiley and Sons, New York, USA 2:493-546

[62] Barros F, Stringheta P (2006) Microencapsulamento de antocianinas-uma alternativa para $\mathrm{o}$ aumento de sua aplicabilidade como ingrediente alimenticio. Biotecnologia Ciencia e Desenvolvimento 36:18-24

[63] Bakowska-Barczak A, Kolodziejczyk P (2011) Black currant polyphenols: their storage stability and microencapsulation. Industrial Crops and Products 34(2):1301-1309

[64] Wagner L, Warthesen J (1995) Stability of Spray-dried encapsulated carrot carotenes. Journal of Food Science 60(5):1048-1053

[65] Cai Y, Corke H (2000) Production and properties of spraydried amaranthus betacyanin pigments. Journal of Food Science 65(6):1248-1252

[66] Ersus S, Yurdagel U (2007) Microencapsulation of anthocyanin pigments of black carrot (Daucus carota L.) by spray dryer. Journal of Food Engineering 80:805-812

[67] Silva G, Constatnt P, Figueiredo R, Moura S (2010) Formulação e estabilidade de corantes de antocianinas extraídas das cascas de jabuticaba (Myrciaria ssp.). Alimentos e Nutrição 21(3):429-436

[68] Reineccius G (1988) Spray-drying of food flavors. Risch S, Reineccius G. Flavor encapsulation. Symposium Series, Washington, USA 55-66

[69] Arburto L, Tavares D, Martucci E (1998) Microencapsulac,ão de óleo essencial de laranja. Ciência e Tecnologia de Alimentos 18:45-48

[70] Bastos D, Araujo K, Rocha-Leao M (2009) Ascorbic acid retaining using a new calcium alginate - Capsul ${ }^{\circledR}$ based edible film. Journal of Microencapsulation 26:97-103

[71] Nagatamo S (1985) Cyclodextrins: expanding the development of their functions and applications. Chemical Economy and Engineering Review 17(7-8):28

[72] Beristain C, Garcia H, Vernon E (1999) Mesquite gum [Propopis juliflora] maltodextrin blends as wall material for spray-dried encapsulated orange peel oil. Food Science and Technology International 5(4):353-356

[73] Pitalua E, Jimenez M, Vernon-Carter E, Beristain C (2010) Antioxidative activity of microcapsules with beetroot juice using gum arabic as wall material. Food and Bioprocess Processing 88(2-3):253-258

[74] Stevens C, Meriggi A, Booten K (2001) Chemical modification of inulin, a valuable renewable resource, and its industrial applications. Biomacromolecules 2:1-16

[75] Roberfroid M (2000) Inulin-Type Fructans: Functional Food Ingredients. CRC Press, Boca Raton, Florida

[76] Johnston-Banks F (1990) Gelatin. Elsevier Applied Science Publishers, London

[77] Bruschi M, Cardoso M, Lucchesi M, Gremiao M (2003) Gelatin microparticles containing propolis obtained by spray-drying technique: preparation and characterization. International Journal of Pharmaceutics 264:45-55

[78] Hugerth A, Sundelöf L (2001) The effect of polyelectrolyte counterion specificity, charge density, and conformation on polyelectrolyte-amphiphile interaction: The carrageenan/furcellaran-amitriptyline system. Biopolymers $58: 186-159$

[79] Glicksman M (1984) Carrageenans. Glicksman M Food hydrocolloids. CRC Press, New York 83-113

[80] Hwang J, Shin H (2000) Rheological properties of chitosan solutions. Korea-Australia Rheology Journal 12:175-179

[81] Klaypradit W, Huang YW (2008) Fish oil encapsulation with chitosan using ultrasonic atomizer. LWT- Food Science and Technology 41:1133-1139

[82] Lee AC, Hong YH (2009) Coacervate formation of alfa lactoalbumin-chitosan and betalactoglobulin-chitosan complexes. Food Research International 42:733-738

[83] Ribeiro A, Neufeld R, Arnaud P, Chaumeil J (1999) International Journal of Pharmaceutics 187:115-123

[84] Chávarri M, Maranón I, Ares R, Ibánez F, Marzo F, Villarán M (2010) Microencapsulation of a probiotic and prebiotic in alginate-chitosan capsules improves survival in simulated gastro-intestinal conditions. International Journal of Food Microbiology 142:185-189

[85] Higuera-Ciapara I, Felix-Valenzuela L, Goycoolea F, Arguelles-Monal W (2003) Microencapsulation of astaxanthin in a chitosan matrix. Carbohydrate Polymers $56: 41-45$

[86] Anjani K, Kailasapathy K, Phillips M (2007) Microencapsulation of enzymes for potential application in acceleration of cheese ripening. International Dairy Journal $17: 79-86$

[87] Deladino L, Anbinder P, Navarro A, Martino M (2008) Encapsulation of natural antioxidants extracted from Ilex paraguariensis. Carbohydrate Polymers 71:126-134

[88] Young S, Sarada X, Rosenberg M

(1993) 
Microencapsulating properties of whey proteins. 1 . Microencapsulation of anhydrous milk fat. Journal of Dairy Science 76:2868-2877

[89] Loksuwan J (2007) Characteristics of microencapsulated bcarotene formed by spray drying with modified tapioca starch, native tapioca starch and maltodextrin. Food Hydrocolloids 21: 928-935

[90] Spada C, Zapata Norena C, Ferreira Marczak L, Cristina Tessaro I (2012) Carbohydrate Polymers 89:1166-1173

[91] Rocha G, Favaro-Trindade C, Ferreira Grosso C (2012) Microencapsulation of lycopene by spray drying: Characterization, stability and application of microcapsules. Food and Bioproducts Processing 90:37-42

[92] Shu B, Yu W, Zhao Y, Liu X (2006) Study on microencapsulation of lycopene by spray-drying. Journal of Food Engineering 76:664-669

[93] Higuera-Ciapara I, Felix-Valenzuela L, Goycoolea F, Argüelles-Monal W (2004) Microencapsulation of astaxanthin in a chitosan matrix. Carbohydrate Polymers $56: 41-45$

[94] Urich K (1994) Comparative Animal Biochemistry. Springer, Germany

[95] Sweeney JP, Marsh AC (1973) Liver storage of vitamin A in rats fed carotene stereoisomers. Journal of Nutrition 103:2025

[96] Mínguez-Mosquera MI, Jaren-Galán M, Garrido-Fernández J (1992) Color quality in paprika. Journal of Agriculture and Food Chemistry 40:2384-2388

[97] Rascon MP, Beristain C, Garcia H, Salgado M (2011) Carotenoid retention and storage stability of spray-dried encapsulated paprika oleoresin using gum Arabic and Soy protein isolate as wall materials. LWT - Food Science and Technology 44:549-557

[98] Bustos-Garza C, Yáñez-Fernández J, Barragán-Huerta B (2013) Thermal and pH stability of spray-dried encapsulated astaxanthin oleoresin from Haematococcus pluvialis using several encapsulation wall material. Food Research International 54:641-649

[99] Barbosa A, Borsarelli C, Mercadante A (2005) Light stability of spray-dried bixin encapsulated with different edible polysaccharide preparations. Food Research International 38:989-994

[100] Tonon R, Brabet C, Hubinger D (2010) Anthocyanin stability and antioxidant activity of spray-dried açai [Euterpe oleracea Mart.] juice produced with different carrier agents. Food Research International 43:907-914

[101] Silva I, Stringheta C, Teofilo F, Nolasco de Oliveira I (2013) Parameter optimization for spray-drying microencapsulation of jaboticaba (Myrciaria jaboticaba) peel extracts using simultaneous analysis of responses. Journal of Food Engineering 117 (4): 538-544

[102] Jimenez-Aguilar D, Ortega-Regules A, Lozada Ramirez J, Perez-Prez M, Vernon-Carter E, Welti-Chanes J (2011) Color and chemical stability of spray-dried blueberry extract using mesquite gum as wall material. Journal of Food Composition and Analysis 24:889-894

[103] Porrarud S, Pranee A (2010) Microencapsulation of Zn- chlorophyll pigment from Pandan leaf by spray drying and its characteristic. International Food Research Journal 17:1031-1042

[104] Hendry G, Houghton J (1996) Natural colorants. Chapman \& Hall, Glasgow

[105] Stinzing F, Carle R (2008) Food Colorants. Chemical and Functional properties. Taylor \& Francis Group, LLC., CRC Press, Boca Raton, FL

[106] Saénz C, Tapia S, Chávez J, Robert P (2009) Microencapsulation by spray drying of bioactive compounds from cactus pear [Opuntia ficus-indica]. Food Chemistry $114: 616-622$

[107] Janiszewska E, Wlodarczyk J (2013) Influence of spray drying conditions on beetroot pigments retention after microencapsulation process. Acta Agrophysica 20(2):343-356

[108] Obón J, Castellar M, Alacid M, Fernández-López J (2009) Production of a red-purple food colorant from Opuntia stricta fruits by spray drying and its application in food model systems. Journal of Food Engineering 90:471-479

[109] Azeredo H, Santos A, Souza A (2007) Betacyanin stability during processing and storage of a microencapsulated red beetroot extract. American Journal of Food Technology 4(2): 307-312

[110] Silva LV, Nelson DL, Drummond MF, Dufossé L, Glória MB (2005) Comparison of hydrodistillation methods for the deodorization of turmeric. Food Research International 38:1087-1096

[111] Hsu C, Cheng A (2007) Clinical studies with curcumin. Advances in Experimental Medicine and Biology 595:471480

[112] Liang JL, Meng YZ, Lei CG (2007) Study on antiseptic effects of curcumin. China Food Additives 2:73-79

[113] Wang Y, Zhang YF, Zhang H, Lu ZX (2007) Study on the stability of microcapsule curcumin. Science and Technology of Food Industry 28(11):193-195

[114] Martins R, Pereira S, Siqueira S, Salomão W, Freitas L (2013) Curcuminoid content and antioxidant activity in spray dried microparticles containing turmeric extract. Food Research International 50:657-663

[115] Carmona M, Martinez J, Zalacain A, Rodriguez-Mendez MA, De Saja JA, Alonso GL (2006) Analysis of saffron volatile fraction by TD-GC-MS and enose. European Food Research and Technology 223:96-101

[116] Javadi B, Sahebkar A, Emami S (2013) A survey on saffron in major Islamic traditional medicine books. Iranian Journal of Basic Medical Sciences, Iran 16

[117] Fernandez J (2004) Biology, biotechnology and biomedicine of saffron. Recent research developments in plant science $2: 127-159$

[118] Ghorpade V, Deshpande S, Salunkhe D (1995) Food colors. Maga J, Tu T. Food additive toxicology. Marcel Dekker, New York 179-233

[119] Mahdavee Khazaei K, Jafari S, Ghorbani M, Hemmati Kakhki A (2014) Microencapsulation of saffron petals's anthocyanins and evaluating their storage stability and color. Carbohyrate polymers 105: 57-62 
[120] Selim K, Tsimidou M, Biliaderis CG (2000) Kinetic studies of degradation of sa€ron carotenoids encapsulated in amorphous polymer matrices. Food Chemistry 71:199-206.
[121] Ersus S (2004) Microencapsulation of anthocyanin pigments of black carrot. Ege Universty, Institution of Science, PhD Thesis: Izmir, Turkey. 